\title{
Perancangan dan Simulasi Antena Mikrostrip Patch Lingkaran Multilayer Parasitic untuk Aplikasi Wireless Local Area Network (WLAN)
}

\author{
Intan Cahyaningtyas', Eva Yovita Dwi Utami ${ }^{2}$ \\ Program Studi Teknik Elektro, \\ Fakultas Teknik Elektronika dan Komputer, \\ Universitas Kristen Satya Wacana, Salatiga \\ 1612015008@student.uksw.edu, ²eva.utami@uksw.edu
}

\begin{abstract}
Ringkasan
Pada penelitian yang dilaporkan ini, difokuskan pada simulasi peningkatan gain antenna mikrostrip dengan bentuk patch lingkaran menggunakan metode multilayer parasitic dan metode DGS (Defected Ground Structure). Rancangan antena yang disimulasikan memiliki frekuensi kerja 5,8 GHz untuk aplikasi WLAN (wireless local area network). Metode multilayer parasitic digunakan untuk meningkatkan gain antena. Sedangkan metode DGS dipilih untuk mengurangi gelombang permukaan yang bisa menurunkan efisiensi antena. Antena yang dirancang dan disimulasikan memiliki 3 layer. Pada layer utama ditempatkan metode DGS berbentuk persegi panjang beserta pencatu antena. Layer end-parasitic ditempatkan di bawah layer utama yang terdiri dari ground dan substrat tanpa patch. Lalu layer front-parasitic ditempatkan di atas layer utama yang terdiri dari substrat dan patch saja tanpa ground. Antena ini dirancang dengan ground berbahan tembaga dengan ketebalan 0,035 $\mathrm{mm}$, bahan substrat berupa FR-4 Epoxy dengan ketebalan 1,6 mm dan permitivitas relatif bernilai 4,6. Setelah dirancang dan disimulasikan, simulasi menunjukkan nilai return loss $-17,548 \mathrm{~dB}$, nilai VSWR 1,299, dan nilai gain 7,08 dB dengan pola radiasi direksional. Dengan menggunakan metode multilayer parasitic simulasi rancangan antena menghasilkan peningkatan gain sebesar 5,33 dB. Hal ini menunjukkan metode multilayer parasitic dapat digunakan untuk meningkatkan gain antena.
\end{abstract}

Kata kunci: Multilayer Parasitic, DGS, returnloss, VSWR, gain

\section{Pendahuluan}

WLAN (wireless local area network) adalah jaringan komputer yang menggunakan gelombang radio sebagai media transmisi data. Bentuk implementasi dari WLAN ini adalah Wi-Fi (Wireless fidelity). WLAN bekerja pada frekuensi 2,4 GHz dan 5,8 GHz [1]. Untuk mendukung kinerja dari teknologi nirkabel ini dibutuhkan antena. Antena mikrostrip merupakan salah satu jenis antena yang banyak dirancang untuk mendukung teknologi nirkabel, akan tetapi kelemahan dari antena mikrostrip ini adalah memiliki gain yang kecil dan efisiensi yang rendah[2].

Untuk itu dibutuhkan metode khusus untuk meningkatkan gain antena mikrostrip. Salah satunya yaitu metode multilayer parasitic. Teknik multilayer parasitik adalah antena mikrostrip single patch yang disusun secara bertingkat. Gain antena dapat lebih tinggi dibandingkan dengan sebuah patch berlapis tunggal. Semakin tinggi konfigurasi yang 
ditumpuk, semakin besar gain-nya [3][4]. Antena mikrostrip multilayer parasitik terdiri lebih dari satu lapisan. Lapisan pertama merupakan antena utama, lapisan kedua dan seterusnya merupakan elemen parasitik. Ketinggian yang memisahkan masing-masing lapisan, yaitu udara disebut dengan air gap. Sebelumnya sudah dilakukan penelitian metode multilayer parasitic untuk meningkatkan gain pada frekuensi $2,35 \mathrm{GHz}$ untuk aplikasi LongTerm Evolution (LTE) dengan bentuk patch rectangular [3] dan juga pada frekuensi 2,4 GHz untuk aplikasi Wireless LAN [5]. Penelitian lainnya yaitu Supriyanto dan Firmansyah melakukan penelitian multilayer parasitic dengan substrat front-end parasitic pada frekuensi 2,35 GHz dengan bentuk patch lingkaran [6].

Kelemahan antena mikrostrip lainnya adalah terdapatnya gelombang permukaan yang dapat menurunkan efisiensi. Gelombang permukaan ini dapat ditekan dengan menggunakan metode DGS (Defected Ground Structure) seperti yang diusulkan pada penelitian [7]. DGS adalah salah satu cara untuk menekan gelombang permukaan dengan cara menghilangkan (etch) sebagian bidang peradiasi atau ground. Teknik DGS tidak membutuhkan lubang pada substrat. Cukup dengan membuat slot pada ground antena mikrostrip. Pengurangan gelombang permukaan bertujuan agar antena menjadi lebih efisien[7].

Pada makalah ini diusulkan rancangan antena multilayer parasitic menggunakan metode front-end parasitic seperti dalam penelitian Supriyanto \& Firmansyah [6], digabung dengan metode yang diusulkan pada [7] yaitu metode DGS berbentuk persegi panjang, dan frekuensi yang digunakan yaitu 5,8 GHz.

\section{Dasar Teori}

Bentuk patch yang akan digunakan adalah patch berbentuk lingkaran. Hal ini didasari oleh penelitian sebelumnya [8] yang menyimpulkan bahwa patch berbentuk lingkaran lebih efisien dibandingkan dengan antena dengan patch berbentuk segi empat. Antena dengan patch lingkaran memiliki gain yang lebih tinggi walaupun memiliki beamwidth yang hampir sama dengan patch segi empat.

Untuk lebar jari-jari $(\alpha)$ ditentukan dengan[9]

$$
\alpha=\frac{F}{\sqrt{1+\frac{2 h}{\pi \varepsilon_{r} F}\left[\ln \left(\frac{\pi F}{2 h}\right)+1,7726\right]}}
$$

Dengan $\alpha$ adalah dimensi radius sirkular atau jari-jari lingkaran $(\mathrm{mm}), h$ adalah ketebalan substrat $(\mathrm{mm}), \varepsilon_{r}$ adalah permitivitas dielektrik relatif substrat $(\mathrm{F} / \mathrm{m})$, dan $F$ adalah fungsi elemen peradiasi

Untuk menentukan fungsi elemen peradiasi ditentukan dengan[9]:

$$
F=\frac{8.791 \times 10^{9}}{f \sqrt{\varepsilon_{r}}}
$$

Dengan $f$ adalah frekuensi kerja antena, dan $\varepsilon_{r}$ adalah permitivitas relatif bahan substrat $(\mathrm{F} / \mathrm{m})$.

Karena bentuk patch antena merupakan lingkaran maka untuk dimensi ground plane dan substrat minimal bergantung pada besar $\alpha$ dari patch lingkaran[10].

Selanjutnya perhitungan lebar dimensi saluran mikrostripnya menggunakan rumus sebagai berikut[11] :

$$
W_{f}=\left\{\frac{2}{\pi}\left[B-1-\ln (2 B-1)+\frac{\varepsilon_{r}-1}{\varepsilon_{r}}\left\{\ln (B-1)+0,39-\frac{0,61}{\varepsilon_{r}}\right\}\right]\right.
$$


Dengan $\varepsilon_{r}$ adalah permitivitas relatif substrat, $w_{f}$ adalah lebar saluran pencatu, $h$ adalah tebal substrat dan dengan nilai $B$ sebagai berikut[11] :

$$
B=\frac{60 \pi^{2}}{Z_{o} \sqrt{\varepsilon_{r}}}
$$

Untuk menentukan panjang saluran mikrostrip adalah dengan panjang feed $\left(L_{f}\right)$ diasumsikan setengah dari dimensi groundplane[9].

Sedangkan teknik pencatuan yang digunakan pada perancangan antena ini yaitu menggunakan microstrip line feed. Pada teknik ini, pencatuan dilakukan dengan cara menghubungkan line pencatuan dengan patch, dimana patch dan line pencatuan menggunakan bahan yang sama yang difabrikasi dengan cara di-etching-kan[12]. Diketahui dari penelitian [13] dengan menggunakan microstrip line feed VSWR yang didapat akan menjadi lebih baik.

\section{Simulasi dan pembahasan Hasil}

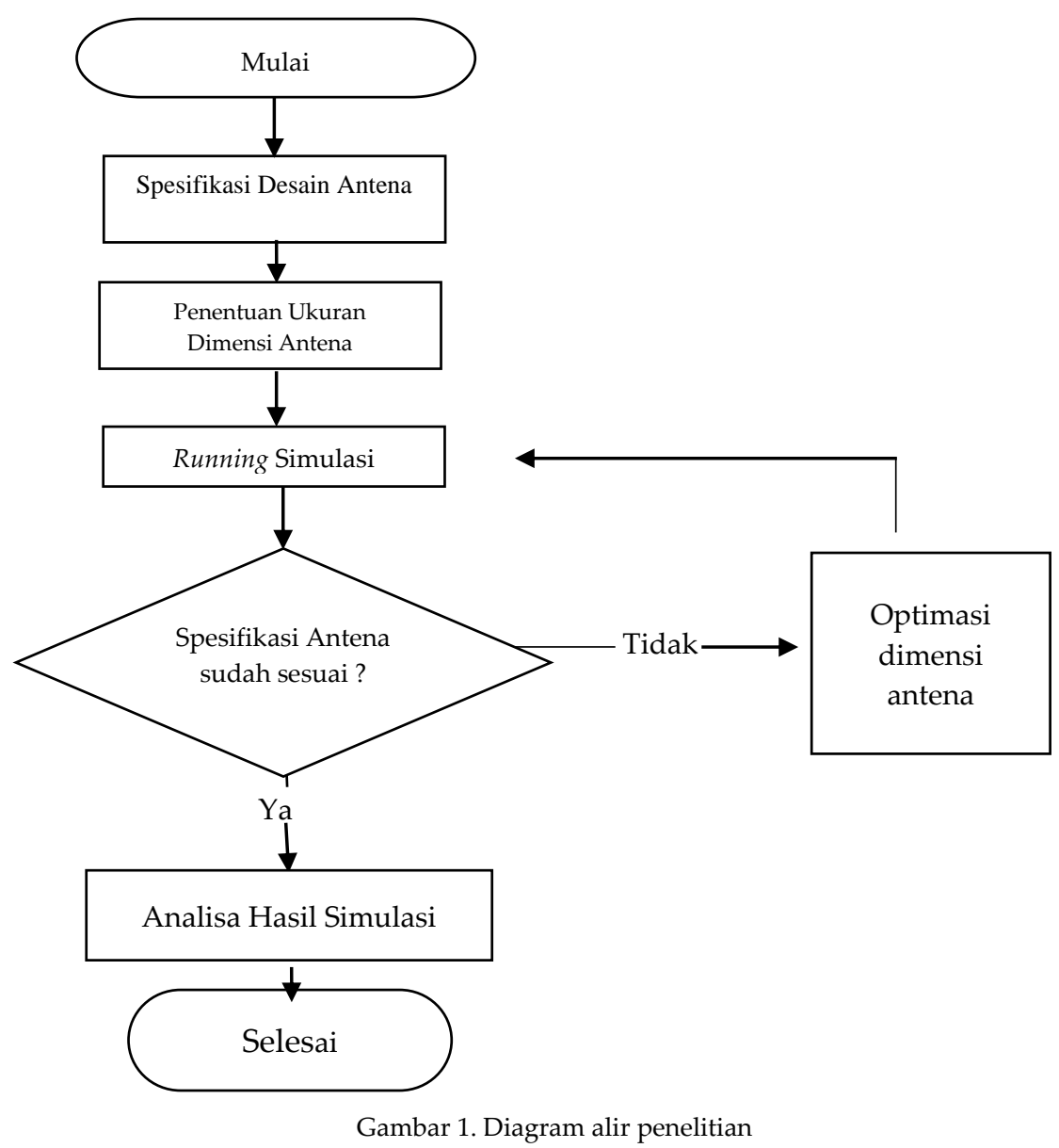

Tahapan yang dilakukan dalam perancangan ini ditunjukkan pada Gambar 1 dengan spesifikasi desain antena seperti yang ada pada Tabel 1. Selanjutnya dipilih bahan yang digunakan yaitu tembaga dengan tebal 0,035 mm untuk ground serta patch dan FR-4 Epoxy dengan tebal 1,6 $\mathrm{mm}$ dan memiliki permitivitas relatif 4,6 untuk substrat. Langkah selanjutnya adalah menentukan dimensi antena mikrostrip patch lingkaran dengan perhitungan matematis menggunakan Persamaan (1) sampai (4). Jika hasil sudah didapat, 
maka langkah berikutnya adalah, mensimulasikannya di dalam CST Microwave Studio 2018. Jika simulasi sudah sesuai dengan spesifikasi maka hasil yang didapat dianalisa. Jika hasil yang didapat belum sesuai maka dilakukan optimasi pada dimensi antena.

Tabel 1. Spesifikasi Antena

\begin{tabular}{|c|c|}
\hline Parameter & Spesifikasi \\
\hline Frekuensi Kerja & $5.8 \mathrm{GHz}$ \\
\hline VSWR & $\leq 2$ \\
\hline gain & $\geq 6 \mathrm{~dB}$ \\
\hline Return loss & $\leq-9,54$ \\
\hline
\end{tabular}

Setelah mendapatkan hasil dimensi antena dengan perhitungan matematis, maka dimensi tersebut disimulasikan ke CST Microwave Studio 2018. Hasil perhitungan dimensi ditunjukkan pada Tabel 2.

Tabel 2. Dimensi Antena berdasarkan Hasil Perhitungan

\begin{tabular}{|c|c|c|}
\hline Parameter & Nilai (mm) & Keterangan \\
\hline$\alpha$ & 5,2 & Jari-jari patch lingkaran \\
\hline$W_{8}$ & 25 & Lebar groundplane \\
\hline$L_{g}$ & 25 & Panjang groundplane \\
\hline$W_{f}$ & 3,26 & Lebar saluran pencatu \\
\hline$L_{f}$ & 12,5 & Panjang saluran pencatu \\
\hline$h_{s}$ & 1,6 & Tebal Substrat \\
\hline$h_{t}$ & 0,035 & Tebal Tembaga \\
\hline
\end{tabular}

Rancangan bentuk antena dengan DGS ditunjukkan pada Gambar 2 sebagai berikut :

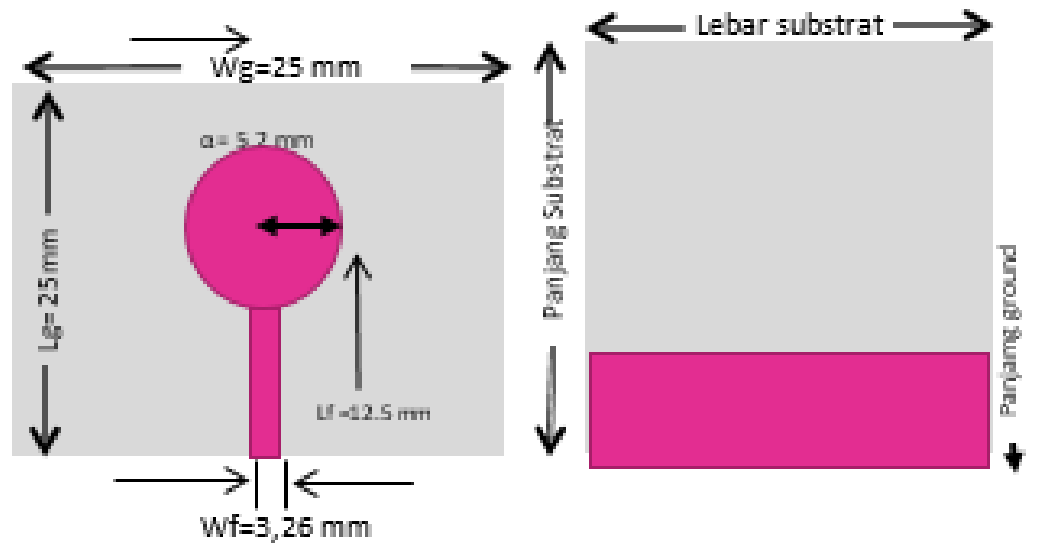

Gambar 2. Perancangan antena dengan DGS berbentuk persegi panjang

\subsection{Antena Elemen Tunggal}

Setelah disimulasikan, diperoleh grafik parameter kinerja antena yang dapat dilihat pada Gambar 3, Gambar 4, dan Gambar 5. 


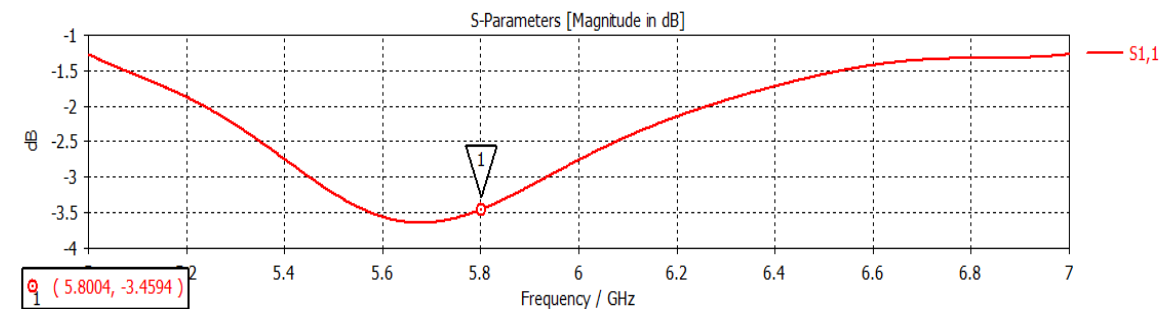

Gambar 3. Return Loss antena elemen tunggal

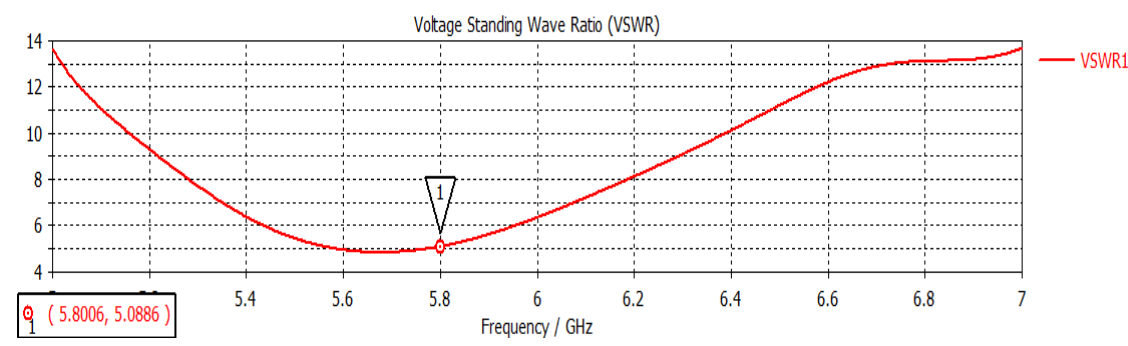

Gambar 4. VSWR antena elemen tunggal

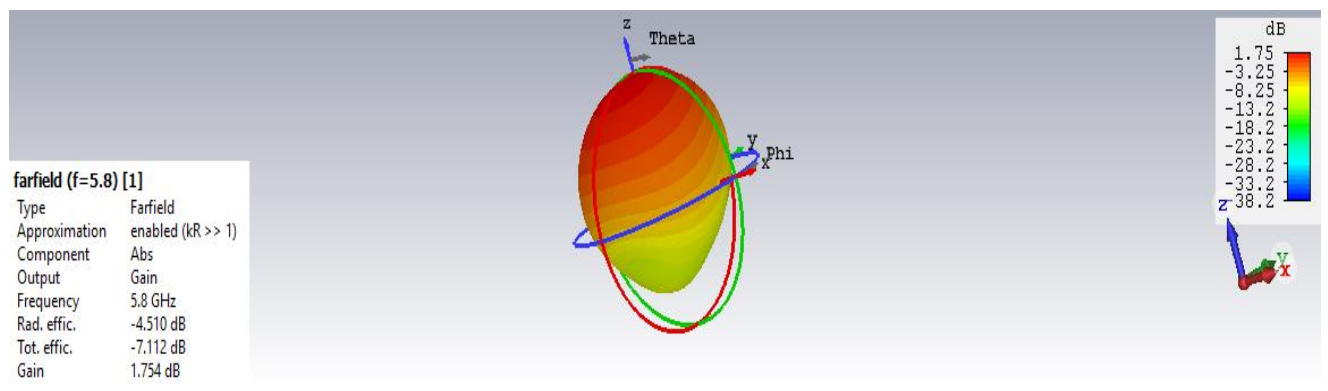

Gambar 5. Gain antena elemen tunggal

Pada Gambar 3 dapat dilihat nilai return loss antena elemen tunggal didapat sebesar 3,459 dB. Pada Gambar 4 nilai VSWR antena elemen tunggal didapat sebesar 5,086. Pada Gambar 5 nilai gain antena elemen tunggal yaitu sebesar 1,75 dB, hal ini menunjukkan nilai return loss, VSWR, dan gain yang didapatkan belum sesuai spesifikasi yang diinginkan.

\subsection{Antena Elemen Tunggal dengan DGS}

Rancangan antena elemen tunggal dengan DGS, disimulasikan dan mendapat grafik parameter antena yang dapat dilihat pada Gambar 6, Gambar 7, dan Gambar 8.

Pada Gambar 6 nilai Return loss yang didapat setelah penambahan metode DGS yaitu $-17,529$ dB. Pada Gambar 7 terlihat nilai VSWR yang didapat dari hasil penambahan metode DGS yaitu 1,306. Terlihat penurunan nilai return loss dan VSWR yang signifikan setelah ditambahkan metode DGS dengan berbentuk persegi panjang. Hal ini sudah sesuai dengan spesifikasi yang diinginkan.

Antena elemen tunggal yang ditambahkan DGS ini menghasilkan gain sebesar 2,25 dB seperti yang tampak pada Gambar 8 . 


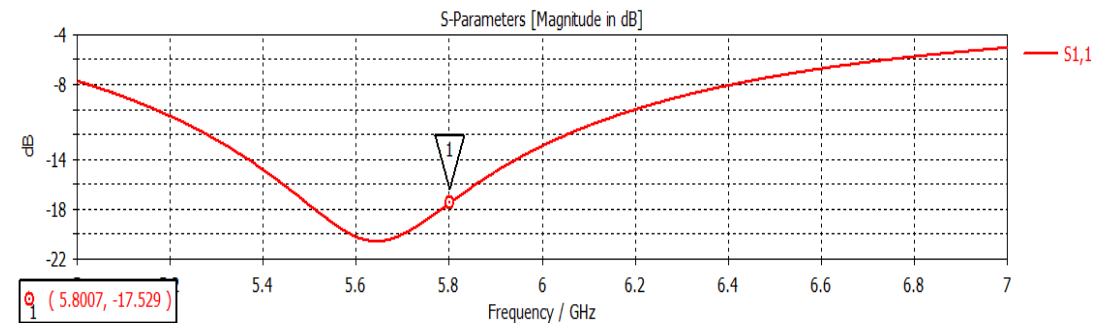

Gambar 6. Return Loss antena elemen tunggal dengan DGS

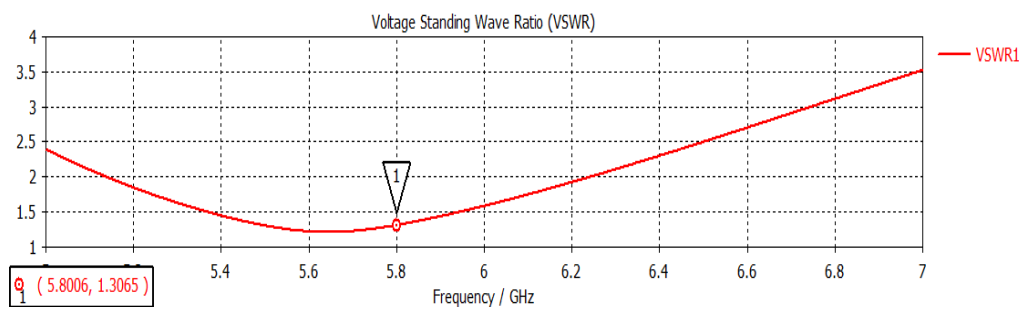

Gambar 7. VSWR antena elemen tunggal dengan DGS

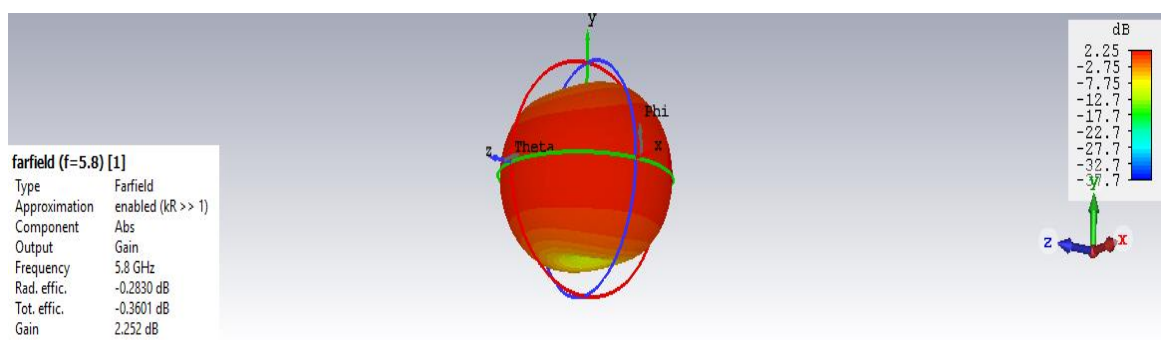

Gambar 8. Gain antena elemen tunggal dengan DGS

\subsection{Antena Multilayer parasitic dengan DGS}

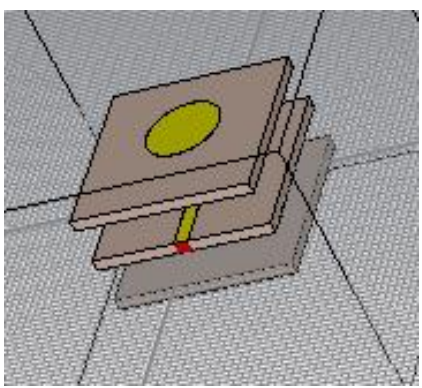

(a)

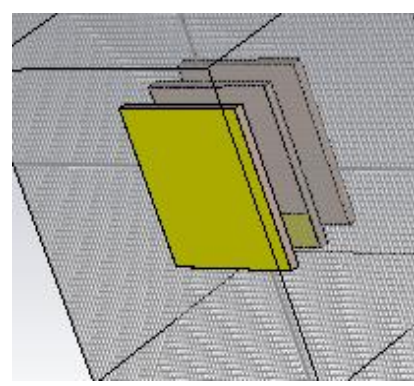

(b)

Gambar 9. Antena mikrostrip dengan Multilayer Parasitic 3 layer (a) Tampak Depan (b) Tampak belakang

Seperti yang terlihat pada Gambar 9, setelah simulasi dengan antena elemen tunggal maka ditambahkan 2 layer antena, yaitu layer end-parasitic dan layer front-parasitic. Layer end-parasitic ditambahkan di bawah layer utama, terdiri dari substrat dan ground tanpa ada patch. Sementara layer front-parasitic ditambah di atas layer utama, terdiri dari substrat dan patch tanpa adanya ground. 


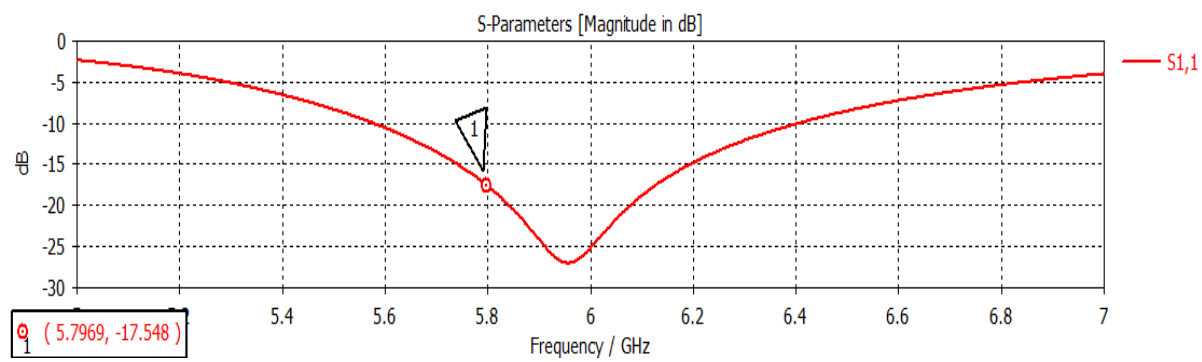

Gambar 10. Return Loss antena multilayer parasitic 3 layer dengan penambahan metode DGS

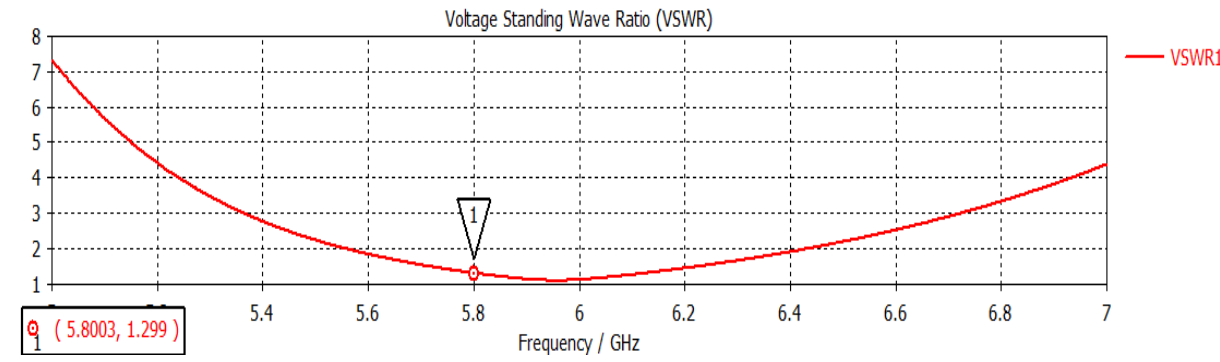

Gambar 11. VSWR antena multilayer parasitic 3 layer dengan penambahan metode DGS

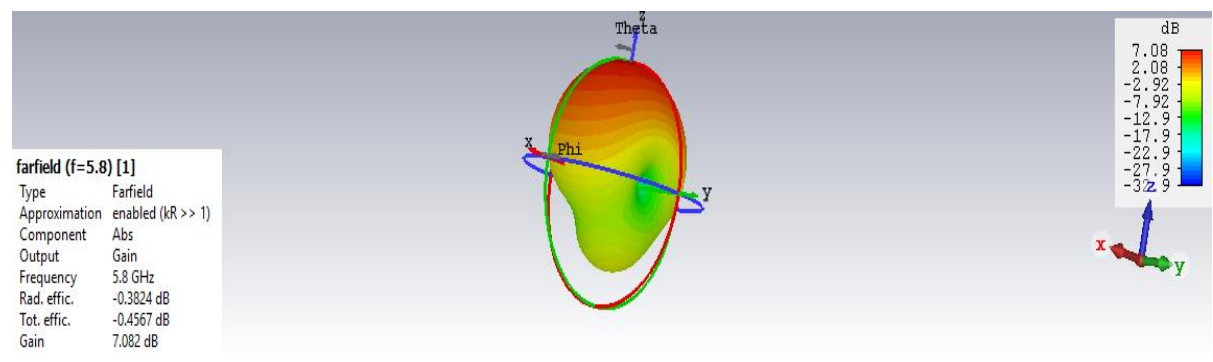

Gambar 12. Gain antena multilayer parasitic 3 layer dengan penambahan metode DGS

Setelah dilakukan simulasi pada rancangan antena multilayer parasitic dengan DGS diperoleh nilai VSWR dan return loss pada Gambar 10 dan Gambar 11, dengan nilai berturut-turut sebesar -17,548 dB dan 1,299. Sedangkan seperti yang terlihat pada Gambar 12 nilai gain yang diperoleh sebesar 7,08 dB. Dengan demikian dapat ditunjukkan bahwa penambahan layer dapat meningkatkan gain antena mikrostrip patch lingkaran.

Pada Gambar 13, pola radiasi yang didapat dari hasil penambahan antena multilayer parasitic 3 layer dengan metode DGS yaitu dihasilkan pola radiasi direksional. Pada gambar tampak pola yang diterima gelombang elektromagnetik lebih efektif hanya pada arah tertentu saja.

Parameter kinerja antena pada simulasi yang telah dilakukan dirangkum pada Tabel 3. 
Farfield Gain Abs (Phi=90)

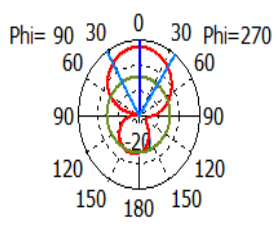

Theta / Degree vs. dB

Frequency $=5.8 \mathrm{GHz}$

Main lobe magnitude $=7.09$

Main lobe direction $=1.0 \mathrm{deg}$

Angular width $(3 \mathrm{~dB})=67.8 \mathrm{~d}$

Side lobe level $=-11.4 \mathrm{~dB}$

(a)

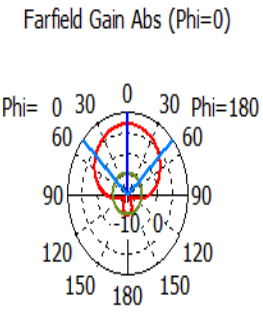

Theta / Degree vs. dB

$$
\text { — farfield }(\mathrm{f}=5.8)[1]
$$

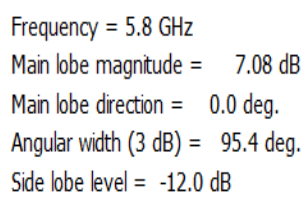

Side lobe level $=-12.0 \mathrm{~dB}$

(b)

Gambar 13. Hasil simulasi nilai pola radiasi antena mikrostrip patch lingkaran dengan multilayer parasitic (a) azimuth (b) elevasi

Tabel 3. Perbandingan Kinerja Antena

\begin{tabular}{|c|c|c|c|}
\hline $\begin{array}{c}\text { Parameter } \\
\text { Kinerja }\end{array}$ & Antena Elemen Tunggal & $\begin{array}{c}\text { Antena Elemen Tunggal } \\
\text { dengan DGS }\end{array}$ & $\begin{array}{c}\text { Antena Multilayer parasitic 3 } \\
\text { Layer dengan DGS }\end{array}$ \\
\hline Return Loss & $-3,459 \mathrm{~dB}$ & $-17,529 \mathrm{~dB}$ & $-17,548 \mathrm{~dB}$ \\
\hline VSWR & 5,086 & 1,306 & 1,299 \\
\hline Gain & $1,75 \mathrm{~dB}$ & $2,25 \mathrm{~dB}$ & $7,08 \mathrm{~dB}$ \\
\hline
\end{tabular}

Pada Tabel 3 dapat dilihat dengan menambahkan DGS dapat memperbaiki nilai Return Loss dan VSWR. Awalnya, nilai return loss pada antena elemen tunggal sebesar -3,459 dB menjadi -17,529 dB. Nilai VSWR antena elemen tunggal sebesar 5,086 menjadi 1,306.

Sementara itu dengan menambahkan layer end-parasitic dan layer front-parasitic dapat menambahkan gain secara signifikan. Awalnya gain antena elemen tunggal bernilai 1,75 $\mathrm{dB}$ ditambahkan DGS menjadi 2,25 dB. Setelah ditambahkan layer end-parasitic dan layer font-parasitic menjadi 7,08 dB.

\section{Kesimpulan}

Berdasarkan simulasi perancangan yang telah dilakukan diperoleh hasil VSWR pada antena patch lingkaran multilayer parasitic dengan DGS sebesar 1,299. Return loss sebesar 17,548 dB, dan gain 7,08 dB. Hasil yang diperoleh telah sesuai spesifikasi perancangan. Dengan penambahan layer parasitic pada antena utama, diperoleh peningkatan gain dari 1,75 dB menjadi 7,08 dB. Sementara itu pola radiasi yang dihasilkan yaitu pola radiasi direksional yaitu antena ini hanya efektif pada satu arah saja. 


\section{Daftar Pustaka}

[1] S.Banerji, R. S. Chowdhury. “On IEEE 802.11: Wreless LAN Technology” International Journal of Mobile Network Communication E Telematics (IJMNCT), Vol. 3, No.4, 2013

[2] F. R. Medina, Edwar, ."Perancangan dan Simulasi Multi layer Parasitic Antena Array 1x2 dengan Patch Persegi Panjang untuk Aplikasi 2,45 GHz", Seminar Nasional Sains dan Teknologi, Jakarta, 17 Oktober 2018.

[3] A.B Santiko, K.Paramayudha, Y Wahyu, Sumartono, H. Wijayanto, "Design and realization multi layer parasitic for gain enhancement of microstrip patch antenna", International Seminar on Intelligent Technology and Its Applications (ISITIA), Lombok, Indonesia, 28-30 July 2016.

[4] R. Abdullah, M.T. Ali, N. Ismail, S. Omar, N. N. S. N. Dzulkefli, . "Multilayer parasitic microstrip antenna array for WiMAX application", IEEE Asia-Pasific Conference on Applied Electromagnetics (APACE), Melaka, Malaysia, 11-13 December 2012.

[5] E.Y.D. Utami, C. Prabelia, F.D. Setiaji, Y. Wahyu, "Peningkatan Gain dengan Teknik Multilayer Parasitic pada Perancangan Antena Mikrostrip Persegi Panjang 2,4 GHz", Jurnal ELKHA, Vol. 11, No.2, pp. 72- 78, Oktober 2019

[6] T. Supriyanto dan T. Firmansyah. "Peningkatan Gain Antena Mikrostrip Lingkaran Menggunakan Parasitik Radiator".Jurnal Ilmiah Elite Elektro, Vol.3, No. 1, pp. 1-5, Maret 2014

[7] L. H. Weng, Y. C. Guo, X. W. Shi, and X. Q. Chen, "An overview on defected groundstructure", Progress In Electromagnetics Research B,Vol.7, pp. 173-189, 2008

[8] T. D. Prasad and K. V. S. Kumar, "Comparisons of Circular and Rectangular Microstrip Patch Antennas," International Journal of Communication Engineering Applications, vol. 02, no. 04, pp. 187-197, 2011.

[9] C.A. Balanis, Antenna Theory: Analysis and Design, USA: John Willey and Son, 2005.

[10]F. Heryanto, "Antena Mikrostrip Patch Sirkular dengan Penambahan Elemen Parasitik Berpolarisasi Sirkular untuk CP-SAR S-Band data Transmit". Skripsi, Universitas Telkom, Bandung, 2018

[11]R. Garg, P. Bhartia, I. Bahl and A. Ittipiboon, Microstrip Antenna Design Handbook, Boston: Artech House, Inc., 2001.

[12]W. L. Stutzman, G. A. Thiele, Antenna Theory and Design, USA: John Wiley and Sons, 2012.

[13]R. Sinaga, A. H. Rambe, . "Analisis Perbandingan antara Saluran Pencatu Feed Line dan Proximity Coupled untuk antena mikrostrip patch Segi Empat". SINGUDA ENSIKOM, Vol. 6 No.3, Maret 2014. 
